\title{
'In good spirits' and the achievement of material satisfaction: Evidence from Argentina
}

\author{
Belen Mesurado ${ }^{1}$, Ricardo F Crespo ${ }^{1}$, Pablo Schiaffino ${ }^{2}$
}

\begin{abstract}
Previous literature has been committed to study the impact of socio-economic variables on material life satisfaction and to study the impact of mental health on emotional life satisfaction. However, not many studies have investigated the impact of mental health over material life satisfaction. This paper has two main objectives: it explores the elements that increase satisfaction in Argentinean men and women according to their self-reports, and to study the influence of socioeconomic variables and the absence of pathological symptoms in the prediction of emotional and material satisfaction. One thousand twelve Argentinean participants were included in this study, about 47.4\% were male and age ranged from 18 to 91 years. Concerning the first objective, results have shown that to earn more money and personal fulfilment at work comes up with a $46.6 \%$ of the answers in men and $37.83 \%$ in women. But, paradoxically, the second objective evidences that socioeconomic variables are associated with material satisfaction but not with emotional satisfaction while absence of pathological symptoms are related to both material and emotional satisfaction.
\end{abstract}

Keywords: material satisfactions, emotional satisfaction, absence of pathological symptoms, socioeconomic variables.

1. Universidad Austral, Consejo Nacional de Investigaciones Científicas y Técnicas (CONICET)

2. Universidad Torcuato Di Tella

Address for correspondence: bmesurado@austral.edu.ar

Date of first (online) publication: 19th September 2019 


\section{Introduction}

According to the OCDE's Better Life Index, life satisfaction measures how people evaluate their life as a whole rather than their current or specific feelings. It aims to capture a whole global perspective of which life circumstances are important for subjective well-being. Previous literature studying the fundamentals of life satisfaction range from income, education, age, crime, health, age or weather just to mention a few (De Neve \& Oswald, 2012; Cuñado \& Pérez de Gracia, 2012; Hanslmaier, 2013; Koivumaa-Honkanen et al, 2014). Many instruments and techniques have been used to try to understand people's conception of their level of life satisfaction. The summing of different satisfaction's domains - like family, finances friends, labor, social and neighbor satisfactions- results in the final value of total life satisfaction.

The exercise we propose in this paper is to analyze the determinants of material and emotional satisfaction (or well-being). Material well-being is defined as a psychological domain entailing satisfaction (or dissatisfaction) with one's income, the evaluation of one's standard of living, the financial satisfaction in general and the acquisition, possession and maintenance of material goods (see Sirgy, 2012, p. 325). Furby (1978) argues that material satisfaction can affect general life satisfaction. Possible explanations rely on the existence of a compensation effect serving the material domain as substitution of other domains (for example, satisfaction with the family, friends, job, etc). Once a certain domain goes down below a certain boundary (e.g., family life) maximizing agents look to increase another domain (e.g., material life) as a mechanism of compensating. On the other hand, what we understand as emotional satisfaction is a mixture of social, family and marital well-being. There are a variety of definitions and conceptualizations of these three forms of well-being (see for example Sirgy, 2012, Chapter 20).

The motivation of this paper is to analyze how income, general education and children (let's label this group as 'socioeconomic variables'), and stress, lack of energy, depression, panic attacks and the use of tranquilizers (psychological mental health) affects well-being. Grouping our well-being variables between material satisfaction (satisfaction with the job, satisfaction with the personal financial situation, satisfaction with the neighborhood and satisfaction with the house) and emotional satisfaction (satisfaction with the family, satisfaction with couple, satisfaction with friends) we are interested to analyze how do these domains are affected by the absence or not of these pathological symptoms and socioeconomic variables.

\section{Income}

Trying to explain general life satisfaction has been the commitment of many 
researchers. A classical - and founding relation - was the Easterlin paradox, which states that there should not be any effect of income on life satisfaction over time (Easterlin, 1974). Even though effects of income on happiness may yet be present at a particular moment, this result should not be persistent throughout the years. Here and there - Powdthavee (2007) and Veenhoven and Hagerty (2006) present useful reviews - literature has been trying to explain this phenomenon capturing the relative importance of income suggested by Easterlin. Graham (2008) argues that humans are on a hedonic treadmill whereby happiness increases until basic needs are satisfied, but then relative - rather than absolute - income matters. Other stories approaching an adaptation effect (Frey \& Stutzer, 2002; Di Tella \& MacCulloch, 2008) were used to justify the low importance of income.

However, other authors do not agree, Stevenson and Wolfers (2008) find income coefficients of 0.3 and 0.36 within and between countries respectively and both statistically significant. They also obtain a positive time series effect for most of the countries - with the US being the exception. Stevenson and Wolfers conclude that there is room for both, absolute and relative income effects to account for people's happiness. In a much recent paper, Stevenson and Wolfers (2013) find no support for the claim 'until basic needs are satisfied' pointed by Graham (2008). Powdthavee (2010) finds that when controlling for endogeneity, not only income coefficients remain statistically significant but also the income effect is almost twice as large as the estimate in the basic specification.

\section{Education and children}

The idea of a relative impact of income leaves room to explore similar related variables and their impact on life satisfaction. Education, for example, is another classical variable related to the level of income. Shall more educated people be more satisfied with their life? Are there diminishing returns as in the case of income? Recent literature claim that education affects positively life satisfaction (Cheung $\&$ Chang, 2009) posing much of the discussion onto the mechanism operating. More educated people can be happier because they earn more and therefore, with an increasing financial satisfaction, general life satisfaction also growths. Cuñado and Pérez de Gracia (2012) find that people with a higher education possess higher incomes. But, after controlling by income and other socio-economic variables, the authors find that education still has a positive impact on life satisfaction. This result implies that a 'self-confidence' effect from acquiring knowledge positively affects life-satisfaction. Davis and Friedrich (2004) comment on the presence of 'knowledge about aging', meaning that the possession of knowledge allow people to adapt more easily across life. In particular, as people show greater knowledge of aging, the higher the life satisfaction.

Previous research on the relation between parenthood and life satisfaction shows 
that parents of minor children are not more satisfied with their lives than people who do not have children (Schiaffino \& Tetaz, 2014). Schiaffino and Tetaz (2014) find that coefficients associated with having children were almost never statistically significant, and when they were, having one child was found to be detrimental for life satisfaction. Possible explanations are that children actually increase emotional satisfaction but there are other shadow variables like 'raising-cost' of children act as suppressors of material satisfaction.Pollmann-Schult (2014) finds that 'parenthood by itself has substantial and enduring positive effects on life satisfaction' but these effects are offset by financial and time costs of parental activity.

\section{Health}

Health - self-reported health, objective health (measured as the presence or not of illness) and psychological mental health - can influence wellbeing. Both three shares the common pattern that good health is a factor that contributes to life satisfaction in a considerable way, as healthy people are more satisfied than sick people. Increasing values of good self-subjective reported health are related higher with life satisfaction (cf. Weinzierl, 2005; Helliwell \& Puntman, 2004). Van Pragg et al. (2003) argue that overall health is the most important - among different domains satisfaction in explaining life satisfaction. On the objective health, evidence shows that greater pain tolerance (Howell et al., 2007), good cardiovascular health (Blanchflower \& Oswald, 2008) and increased longevity (Helliwell, 2011) are associated with increasing life satisfaction. Even disability is detrimental of lower life satisfaction (Oswald \& Powdhavthee, 2005). In a nutshell, it seems that previous literature agrees on the idea that good objective and subjective health are associated with higher subjective well-being.

When it comes to matter with psychological mental health, even in the case that variables can be overlapping, evidence shows a strong and negative high correlation between well-being and psychological illness. Diener and Seligman (2004) argue that mental disorders cause widespread suffering in terms of people's well-being. More specific studies present evidence that depressive symptoms have considerable impact on wellbeing (Beekman et al, 2002; Cummins, 2013). Bipolar disorder and schizophrenia are associated with significantly lower levels of well-being (Stoll el al, 2012).

\section{Present study: evidence from Argentina}

Studies of life-satisfaction over Argentina are relatively new. We can only account for a few studies on the economics of happiness using data from Argentina. In a special survey that evidences some contradiction within the Argentinean populations, 
Giarrizzo (2008) finds that although nearly of $85 \%$ of the people evaluated their economic situation as either 'very bad', 'bad' or 'regular', but a notorious majority (73.5\%) considered itself 'happy' or 'very happy'. Interestingly, when they were asked to answer what factors would make them happier, an amazing $82 \%$ suggested economic related aspects, like a higher income or a better job. In the same year, another paper by Cruces, Ham and Tetaz (2008) offer an analysis of life satisfaction at a neighborhood level. The quality of the neighborhood, income, satisfaction with friends, mental health and emotional life had a positive impact on happiness. The same study has shown important gender differences, males were happier, on average, than women.

Much recent work by Gongora and Castro Solano (2014) investigate the relationship between three different aspects of wellbeing (pleasant life, engaged life and meaningful life) to life satisfaction in Argentinean adolescents. They found that only the engaged life had a moderate association with life satisfaction and it was also the only significant predictor of this variable. Consequently, authors concluded that eudemonic life appears to be more important in predicting life satisfaction than the hedonic life. Schiaffino and Tetaz (2015), and Tetaz, Schiaffino and Braun (2015) find no relation between socioeconomic status and happiness. In that survey, Argentineans answer how active they were in several domains of their lives, and the fundamentals of life satisfaction were the level of family activity, social life, and the time spent with fiancé. In accordance with Easterlin seminal paper, Schiaffino and Tetaz (2015a) show that improvements in life satisfaction did not correlate with the satisfaction of the financial situation in households but, perceived satisfaction with the financial situation of households in a specific moment affects life satisfaction indeed (but it does it less than proportionally). Moreover, social class status and income affect life satisfaction in some but not in all the waves the authors considered, in the last case suggesting that it does not matter unless you cannot cover the basics.

Finally, Schiaffino and Tetaz (2014) show that - similar with income gains and losses - the value function associated with neighborhood quality of life is steeper in the domain of losses compare with the space of gains, when it comes to the position of a neighborhood relative to others in terms of security. The perception that living in a safer neighborhood improves the perceived quality of life in that place does exist, but the magnitude of the difference is smaller than the one caused by the opposite sensation.

Based on this background, the objectives of this paper are:

1. To explore the elements that increase satisfaction in Argentinean men and women according to their self-reports.

2. To study the influence of socioeconomic variables (income, children, participants' education level, the head of household's education level), and the absence of pathological symptoms (depression, panic attacks, use of tranquilizers or sedatives, stress, lack of energy, or listlessness) in the prediction of emotional 
and material satisfaction.

\section{Method}

\section{Participants}

One thousand and twelve Argentinean participants were included in this study. About 47.4\% were male, with ages ranging from 18 to 91 years $(M=42.59, S D=$ 17.01). About $9 \%$ of the sample lives in Buenos Aires capital; $25 \%$ lives in Greater Buenos Aires conurbation, which includes several Buenos Aires Province districts, and 66\% lives in the rest of the provinces outside of Buenos Aires. The socioeconomic composition is also representative of that of Argentina as a whole; just 5\% belongs to the upper class, whereas $38 \%$ is consider middle class, $32 \%$ is lower-middle class, and $24 \%$ is low class.

\section{Ethical Procedures}

Participants were informed of the purpose of the study, and they signed an informed consent form. No further incentives were given for participation. The instruments were administered personally for evaluators, under the supervision of the research staff. All tests were completed in a single session.

\section{Research Instruments}

The instruments were a self-administered questionnaire. It included the following questions and scale:

1. We used an open-ended question 'What would make you feel more satisfaction?' to explore the elements that increase satisfaction in Argentinean men and women. Later the answers were coded.

2. Social economic variables. To measure the socio-economic variables we asked about (a) an income proxy using social class status. We divided participants into four differentiated groups: upper-class, middle class, lower-middle class and low-class according to income informed by participants (b) children: 'Do you have any children? Yes/No', (c) We evaluated participants' education level and, (d) the head of household's education level using four response alternatives 'no education, complete primary education, complete secondary education, and tertiary/university education.' 


\section{Absence of pathological symptoms}

To measure presence or absence of pathological symptoms we included the following dichotomous questions (a) depression: 'Have you felt depressed in the last 12 months? Yes/No', (b) panic attacks: 'Have you had panic attacks in the last 12 months? Yes/ No', (c) use of tranquilizers or sedatives: 'Have you taken tranquilizers or sedatives in the last 12 months? Yes/No', (d) stress: 'Have you felt stressed in the last 12 months? Yes/No', (c) lack of energy or listlessness, 'Have you felt lack of energy or listlessness in the last 12 months? Yes/No'

\section{Emotional and material satisfaction}

We developed a new scale to measure emotional and material satisfaction. Material satisfaction subscale consists of three items that were summed, with response format ranges from 1 (unsatisfied) to 10 (strongly satisfied) (e.g., how satisfied are you with your financial situation?). Emotional satisfaction subscale consists of four items that were summed, with response format ranges from 1 (unsatisfied) to 10 (strongly satisfied) (e.g., How satisfied are you with your family?). To study the validity of this scale we carried out an Exploratory Factor Analysis (EFA), the KMO was .80. The method of principal Components and Varimax solution was employed. The EFA of items showed two factors: material satisfaction $(\alpha=.75)$ and another one related to emotional satisfaction $(\alpha=.68)$. The model explained $60 \%$ of the variance.

\section{Statistical procedure}

Structural equations modeling analyses were conducted to explore the influence of socioeconomic variables and the absence of pathological symptoms in the prediction of emotional and material satisfaction, by using the software program AMOS 16.0 (SPSS Inc. 2007). 'Structural equation modeling (SEM) is a statistical methodology that takes a confirmatory (i.e., hypothesis-testing) approach to the analysis of a structural theory bearing on some phenomenon (...) The hypothesized model can then be tested statistically in a simultaneous analysis of the entire system of variables to determine the extent to which it is consistent with the data. If goodness-of-fit is adequate, the model argues for the plausibility of postulated relations among variables; if it is inadequate, the tenability of such relations is rejected' (Byrne, 2010, p. 3). Following the two-step modeling approach recommended by Anderson and Gerbring (1988), we tested a measurement model of the hypothesized latent variables before evaluation our structural model. Confirmatory factor analysis was used to test the factor structure of the latent constructs. The following goodness of fit indices were used: Chi-square, the ratio of the Chi-square statistic to degrees of freedom $\left(\chi^{2} / \mathrm{df}\right)$, the goodness of fit index (GFI), adjusted goodness of fit index (AGFI) and bentler-bonett normed fit index (NFI). Root mean square error of approximation (RMSEA) were used to measure error. 


\section{Results}

\section{Elements that could increase satisfaction in Argentinean men and women according to their self-reports}

The first aim of this study was to explore the elements that increase satisfaction in Argentinean men and women according to their self-report. The table 1 summarizes the answers of males and females.

Table 1.

Elements that would increase satisfaction in Argentinean men and women

\begin{tabular}{lrrrr}
\hline & \multicolumn{2}{c}{ Male } & \multicolumn{2}{c}{ Female } \\
& Frequency & $\%$ & Frequency & $\%$ \\
\hline Earn more money & 114 & 23.5 & 98 & 18.7 \\
Personal fulfilment at work & 112 & 23.1 & 103 & 19.13 \\
Family/children & 60 & 12.4 & 85 & 16.1 \\
Better health & 47 & 9.6 & 66 & 12.6 \\
Peaceful life & 35 & 7.2 & 44 & 8.4 \\
Travel & 30 & 6.1 & 37 & 7.1 \\
Study & 21 & 4.3 & 24 & 4.5 \\
Go out with friends and have fun & 20 & 4.2 & 17 & 3.2 \\
Do something for society & 15 & 3 & 16 & 3 \\
Partner & 9 & 1.8 & 6 & 1.1 \\
Religions & 2 & 0.4 & 7 & 1.4 \\
Miscellaneous & 21 & 4.3 & 23 & 4.6 \\
\hline
\end{tabular}

\section{Socioeconomic and pathological symptoms}

About $70.5 \%$ had children. About $7.2 \%$ of participants had no education, $47.2 \%$ had complete primary education, $35.1 \%$ had complete secondary education, and $10.5 \%$ had tertiary/university level. Regarding, head of household's education level about $7.5 \%$ had no education, $50.1 \%$ had complete primary education, $28.9 \%$ had complete secondary education, and 13.5\% tertiary/university level. Table 2 displays frequency and percentage of absence of pathological symptoms in the participants.

Table 2

Frequency and percentage of absence of pathological symptoms in the participants

\begin{tabular}{lcc}
\hline Absence of & Frequency & $\%$ \\
\hline Depression & 869 & 85.9 \\
Panic attacks & 937 & 92.6 \\
Use of tranquilizers or sedatives & 867 & 85.7 \\
Stress & 718 & 70.9 \\
Lack of energy or listlessness & 673 & 66.5 \\
\hline
\end{tabular}




\section{Relations between socioeconomic variables and absence of pathological symptoms to emotional and material satisfaction}

The second aim of this study was to study the influence of socioeconomic variables (income, children, participants' education level, the head of household's education level) and the absence of pathological symptoms (depression, panic attacks, use of tranquilizers or sedatives, stress, lack of energy, or listlessness) in the prediction of emotional and material satisfaction. To study this model we carried out a Structural Equation Modeling (SEM) the results have shown the theoretical model fit the data well, $\chi^{2}(41)=329.8, p \leq .001, \chi^{2} / \mathrm{df}=8.04 ; \mathrm{GFI}=.95 ; \mathrm{AGFI}=.91, \mathrm{CFI}=.90$, RMSEA $=.08$ and it is depicted in Figure 1. As it can be seen in Figure 1, socioeconomic variables have a positive influence only on material satisfaction but not on emotional satisfaction however, the absence of pathological symptoms have a positive influence on both material and emotional satisfaction.

Figure 1. Model

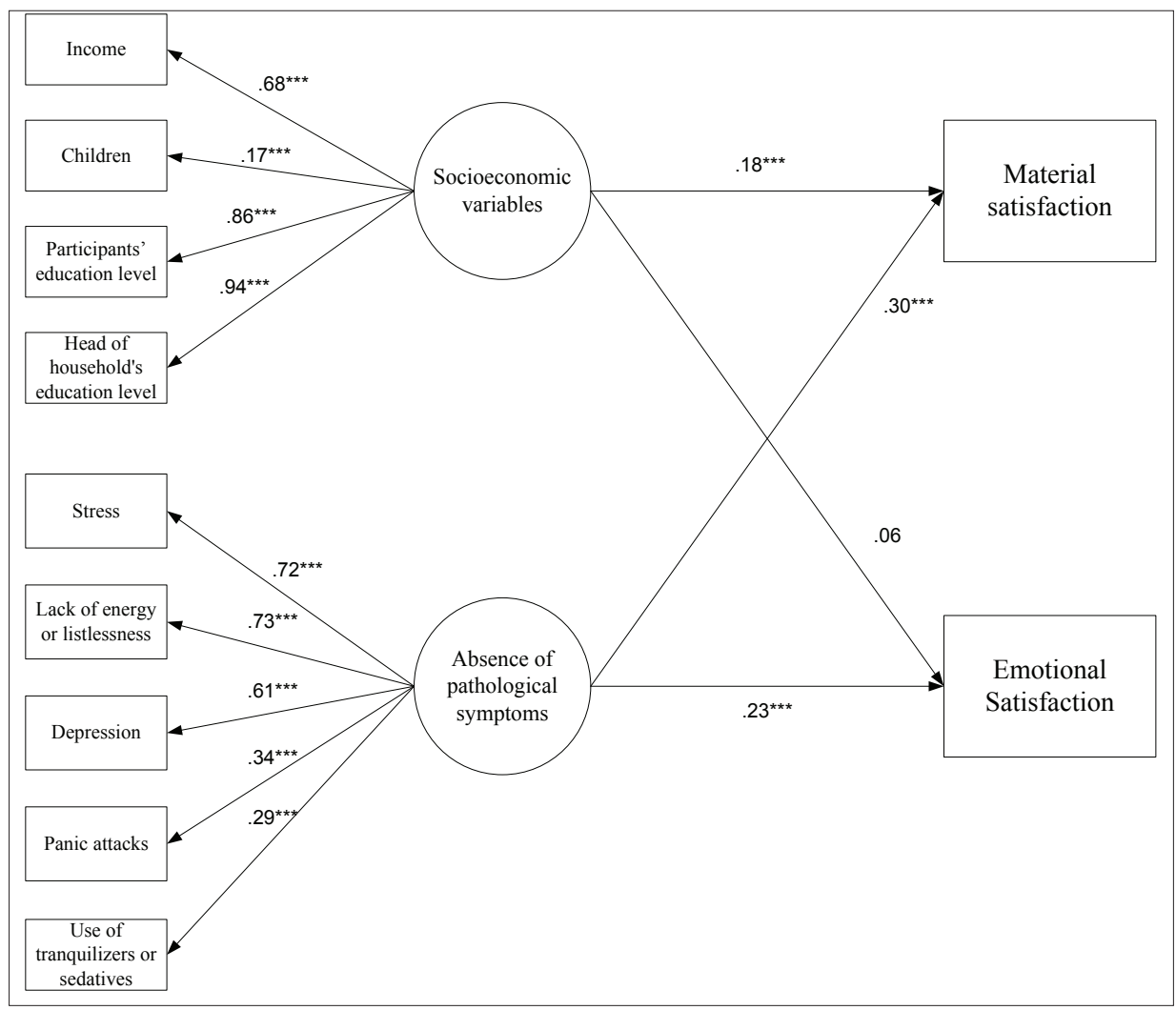




\section{Discussion}

The first goal of our paper was to explore the elements that increase satisfaction in Argentinean men and women according to their self-report. We started with the open question, 'what would make you feel more satisfaction?' To earn more money and personal fulfilment at work comes up with a $46.6 \%$ of the answers in men and $37.83 \%$ in women. These results approximately coincide with those results already commented by Giarrizzo (2012) for the years 2006 and 2007 when she asked people of middle class what would make them happier. In the same way, a previous study found that Argentinean adolescents tend to look for immediate pleasures (pleasant life) more than an engaged life (commitment, perseverance and a sense of having been called to do what one does) and a meaningful life (Gongora \& Casto Solano, 2014). Although, unlike the Gongora and Casto Solano study, our study was developed in adults seem that Argentinean people attribute a high importance to hedonistic aspect of well-being, and likely that is why they reported the money and personal fulfilment at work as the first satisfaction sources.

Moreover these results could be explained by economic reasons, according to Tony Atkinson and Salvatore Morelli (2011) study about crises and inequality, Argentina is at the top of the list of countries suffering financial crises with 7 crises in the last 100 years, at the top of 'real per-capita GDP disasters (1911-2006)' with 9 disasters and at the top of 'real per-capita Consumption disasters (1911-2006)' with 10 disasters. Maybe this bad performance affects the perception of earnings and satisfaction at work as elements relevant for wellbeing in Argentinian population.

Furthermore, our finding shows some gender differences about elements that can increase wellbeing, for example for women, family/children and to have a better health seem to be more important for their satisfaction than for men (family/children and better health is $28,7 \%$ for women and is $22 \%$ for men). This could be explained in part by the socially attributed roles to women, given that the delegation of child rearing and family care responsibilities primarily to women and that makes it easier for men to continue pursuing their career or economic development. Research has consistently shown that women are more likely to interrupt their careers or regular sources of income - even when they work in high prestige jobs- due to familiar reasons (Kirchmeyer, 1998; Lyness \& Thompson, 1997). Consequently, it would seem that for women the economic factor as a source of satisfaction would be more secondary than for men, at least when satisfaction is measured by self-report.

The second goal aimed to study was to test a theoretical model which proposed to study the relationships of socioeconomic variables (income, children, participants' education level, the head of household's education level) and absence of pathological symptoms (depression, panic attacks, use of tranquilizers or sedatives, stress, lack of energy, or listlessness) with two different aspects of satisfaction: material and emotional. Our results have shown that socioeconomic variables are associated with material satisfaction but not with emotional satisfaction. Income is the flow 
of economic resources that an individual or household receives over time. Income enhances individuals' freedom to choose where and how to live, where to study and offers the possibility of better material conditions for family. Moreover presence of children in the family, and educational levels, as were expected, were also related to material satisfaction in participants.

However, it is important to highlight that socioeconomic variables were not associated with emotional satisfaction (measured as social, family and marital wellbeing). That indicating that the income, education and presence of children not necessarily guarantee good emotional relationships with friends, partner, and overall family. These results are consistent with Castro Solano study (2011) who found that hedonic life was not associated with life satisfaction in adults while eudemonic life was strongly correlated with it. This shows once again that, material domain does not replace others life essential domains as for example, satisfaction with the family, friends, and partner.

Moreover our model has shown that absence of pathological symptoms is related to both material and emotional satisfactions. Also, it is important to note that influence of absence of pathological symptoms on material satisfaction is stronger than the influence of socioeconomic variables on it. Given that the relationship between mental illness and wellbeing is strong, several studies suggest that measurement of wellbeing is also valid for measuring mental illness - as clinical depression, - which is characterized by the three cores: lack of positive mood, interests, and energy. For example, a recent study by Krieger et al. (2014) indicated that the World Health Organization Wellbeing Index (WHO-5) performs well especially in detecting mild to moderate levels of depression.

Based on this referenced, it is not strange to find that absence of pathological symptoms is associated with both material and emotional satisfactions. The current study reveals a remarkably strong and consistent association between absences of pathological symptoms with material satisfaction. This finding is in line with previous research which have found that mental disorders are overrepresented in, for example, the lower social strata (Hudson, 2005; Miech, Caspi, Moffitt, Wright, $\&$ Silva, 1999). This suggest that worse mental health is associated with a worse material satisfaction. Moreover, De Neve and Oswald (2012) find a positive affect (indicator of absence of pathology) could predict the income (or material satisfactions) in adolescents and young adults. Ng and colleagues (2014) argue that the association between socioeconomic status and mental health is one of the most firmly established patterns in psychiatric epidemiology; the most privileged tend to experience the best mental health outcomes while the most deprived tend to experience the worst one.

Our findings denote a certain paradox when comparing the results of the first and the second goals: while people declare that more earnings and a better job would make them happier, these variables (measured in the model into socioeconomic variables) have little influence on material and emotional satisfaction. This might have to do with a phenomenon noted by Brickman, Coates and Janoff-Bulman 
(1978) and also highlighted by Di Tella and McCulloch (2006, p. 34): a small sample of individuals who had won between $\$ 50,000$ and $\$ 1,000,000$ at the lottery the previous year reported 'comparable' life satisfaction levels as those who did not. This is presented as an example of 'adaptation level theory', which suggests that contrast and habituation operate to prevent the winning of a fortune from elevating happiness as much as might be expected (Although Gardner and Oswald (2006) show exactly the contrary: winning lottery has longstanding effects on mental well-being). Though people appraise material assets as a way of increasing satisfaction, they diminish its assigned relevance when they have them. In contrast, 'health assets' seems to have a sensible impact not only over emotional satisfaction, but also in material satisfaction.

\section{Conclusion}

In sum, this research made some contributions regarding hedonic and eudemonic well-being. In the first place, our results highlight the importance attributed by Argentinean adults to hedonic well-being (objective 1), while at the same time they show that hedonic well-being cannot predict emotional satisfaction (objective 2). However, promoting mental health seems to be the most appropriate way to achieve an emotional and even material satisfaction (objective 2). Consequently it may be appropriate to develop public policies that contribute to caring for and improving the mental health of their habitats.

\section{Limitations}

A limitation of the present study comes from the use of a one-time self-report, which means that there is an inherent method effect contributing to the strength of all of the correlations. The study was based on cross-sectional data, so the direction of the effects in the models is not clear. Furthermore, another important limitation is that we measured the presence or absence of mental illness but the absence of mental illness does not imply the presence of mental health, as it is indicated by Keyes (2013). In a future study, we would necessarily include other instruments to evaluate mental illness or mental health, and test the model with longitudinal data.

\section{References}

Atkinson, T. \& Morelli, S. (2011) Economic crises and Inequality. Human Development Research Paper 2011/06, http://hdr.undp.org/sites/default/files/hdrp_2011_06.pdf 
Beekman, A. T., Penninx, B. W., Deeg, D. J., Beurs, E. D., Geerlings, S. W., \& Tilburg, W. V. (2002) The impact of depression on the well-being, disability and use of services in older adults: a longitudinal perspective. Acta Psychiatrica Scandinavica, 105, 1, 20-27

Blanchflower, D. G., \& Oswald, A. J. (2008) Hypertension and happiness across nations. Journal of Health Economics, 27, 218-233

Brickman P, Coates D, \& Janoff-Bulman R. (1978) Lottery winners and accident victims is happiness relative? Journal of Personality and Social Psychology, 36, 917-927, on line in http://pages.ucsd.edu/ nchristenfeld/Happiness_Readings_files/Class\%203\%20-\%20 Brickman\%201978.pdf

Castro Solano, A. (2011) Las rutas de acceso al bienestar. Relaciones entre bienestar hedónico y eudamónico. Un estudio en población argentina [The Routes to Access Wellbeing. Relations between Hedonic and Eudaemonic Well-being. A Study in Argentine Population]. Revista Iberoamericana de Diagnostico y Evaluacion Psicologica, 31, 37-57

Cheung, H., \& Chan, A. (2009) The Effect of Education on Life Satisfaction Across Countries. Alberta Journal of Educational Research, 55, 1, 124-136

Cruces G., Ham A. \& Tetaz M. (2008) Quality of Life in Buenos Aires' Neighborhoods: Hedonic Price Regressions and the Life Satisfaction Approach', Working paper for the project 'Quality of Life Urban Neighborhoods in LAC', BID, Research department

Cummins, R. A. (2010) Subjective wellbeing, homeostatically protected mood and depression: A synthesis. Journal of Happiness Studies, 11, 1, 1-17

Cuñado, J., \& de Gracia, F. P. (2012) Does education affect happiness? Evidence for Spain. Social indicators research, 108, 1, 185-196

Davis, N. C., \& Friedrich, D. (2004) Knowledge of aging and life satisfaction among older adults. The International Journal of Aging and Human Development, 59, 1, 43-61.

De Neve, J. E., \& Oswald, A. J. (2012) Estimating the influence of life satisfaction and positive affect on later income using sibling fixed effects.Proceedings of the National Academy of Sciences, 109, 49, 19953-19958

Diener, E., \& Seligman, M. E. (2004) Beyond money toward an economy of well-being. Psychological science in the public interest, 5, 1, 1-31

Di Tella, R., \& MacCulloch, R. (2006) Some uses of happiness data in economics. The Journal of Economic Perspectives, 20, 1, 25-46

Di Tella, R. \& MacCulloch, R. (2008) Happiness Adaptation to Income beyond' Basic Needs'. No. w14539. National Bureau of Economic Research

Easterlin, R. A. (1974) Does Economic Growth Improve the Human Lot? Some Empirical Evidence. In R. David and M. Reder (eds.) Nations and Households in Economic Growth: Essays in Honor of Moses Abramovitz (pp. 89-125) New York: Academic Press

Frey S. \& Stutzer A. (2002) What Can Economists Learn from Happiness Research? Journal of Economic Literature 40, 2, 402-35

Gardner, J. \& Oswald, A. J. (2007) Money and Mental Wellbeing: A Longitudinal Study of Medium-Sized Lottery Wins, Journal of Health Economics, 26, 1, 49-60

Furby, L. (1978) Possession in humans: An exploratory study of its meaning and motivation. Social Behavior and Personality: an international journal, 6, 1, 49-65 
Giarrizzo, V. (2008) Economía y Felicidad: ¿Existe vínculo?. Unpublished

Gongora, V. \& Castro Solano, A. (2014) Well-being and life satisfaction in Argentinean adolescents. Journal of Youth Studies, 17, 1277-1291

Graham C. (2008) Happiness and Health: Lessons and Questions For Public Policy. Health Affairs, 27, 1, 72-87

Hanslmaier, M. (2013) Crime, fear and subjective well-being: How victimization and street crime affect fear and life satisfaction. European Journal of Criminology, 10, 5, 515-533

Heinemann, A. W., \& Whiteneck, G. G. (1995) Relationships among impairment, disability, handicap, and life satisfaction in persons with traumatic brain injury. The Journal of Head Trauma Rehabilitation, 10, 4, 54-63

Helliwell, J. F. (2011) Institutions as enablers of wellbeing: The Singapore Prison case study. International Journal of Well-being, 1, 2, 255-265

Helliwell, J. F., \& Putnam, R. D. (2004) The social context of well-being. Philosophical Transactions of the Royal Society B: Biological Sciences, 359, 1449, 1435-1446

Howell, R. T., Kern, M. L., \& Lyubomirsky, S. (2007) Health benefits: Meta-analytically determining the impact of well-being on objective health outcomes. Health Psychology Review, 1, 1, 83-136

Hudson, C. G. (2005) Socioeconomic Status and Mental Illness: Tests of the Social Causation and Selection Hypotheses. American Journal of Orthopsychiatry, 75, 1, 3-18

Keyes, C. L. M. (2013) Mental Well-Being. International Contributions to the Study of Positive Mental Health Atlanta, GA, USA: Springer

Kirchmeyer, C. (1998) Determinants of managerial career success: Evidence and explanation of male/female differences. Journal of Management, 24, 673-692

Koivumaa-Honkanen, H., Honkanen, R., Viinamaeki, H., Heikkilae, K., Kaprio, J., \& Koskenvuo, M. (2001) Life satisfaction and suicide: a 20-year follow-up study. American Journal of Psychiatry, 158, 3, 433-439

Krieger, T; Zimmermann, J., Huffziger, S., Ubl, B., Diener D., Kuehner C., \& Grosse Holtforth, M. (2014) Measuring depression with a well-being index: Further evidence for the validity of the WHO Well-Being Index (WHO-5) as a measure of the severity of depression. Journal of Affective Disorders, 156, 240-244

Lyness, K. S., \& Thompson, D. E. (1997) Above the glass ceiling? A comparison of matched samples of female and male executives. Journal of Applied Psychology, 82, 359-375

Miech, R. A., Caspi, A., Moffitt, T. E., Wright, B. R. E., \& Silva, P. A. (1999) Low socioeconomic status and mental disorders: a longitudinal study of selection and causation during young adulthood. American journal of Sociology, 104, 4, 1096-1131

Ng, E., Muntaner, C., Chung, H. \& Eaton, W. W. (2014) Socioeconomic Status and Mental Illness. The Wiley Blackwell Encyclopedia of Health, Illness, Behavior, and Society, 2232-2238

Pollmann-Schult, M. (2014), Parenthood and Life Satisfaction: Why Don't Children Make People Happy? Journal of Marriage and Family, 76, 319-336

Powdthavee, N. (2007) Economics of happiness: A review of literature and applications. Chulalongkorn Journal of Economics, 19, 1, 51-73

Powdthavee, N. (2010) How Much Does Money Really Matter? Estimating the Causal Effects 
of Income on Happiness. Empirical Economics, 39, 1, 77-92

Schiaffino, P., \& Tetaz, M. (2016) Income, Sex, Pills and Relationships: An Empirical Study for Argentina. In M. Rojas Handbook of Happiness Research in Latin America (pp. 251-272). Springer: Netherlands

Schiaffino, P., \& Tetaz, M. (2014) Prospect Insecurity:The Asymmetric Effect of Crime Perception on Neighborhood Quality of Life (prepared for The International Forum of Well- being \& Development Policy 24th/26th November 2014 Guadalajara, Mexico)

Sirgy, M. J. (2012) The psychology of quality of life: Hedonic well-being, life satisfaction, and eudaimonia (Vol. 50). Springer: Netherlands

Stevenson, B. \& Wolfers, J. (2008) : Economic growth and subjective well-being: reassessing the Easterlin paradox, CESifo working paper, N. 2394

Stevenson, B., \& Wolfers, J. (2013) Subjective well-Being and income: Is there any evidence of satiation? National Bureau of Economic Research. № 18992

Stoll L, Michaelson J, \& Seaford C. (2012) Well-being evidence for policy: A review. New Economics Foundation: London

Tetaz, M., Schiaffino, P., \& Braun, M. (2015) Argentina's Economic Development and Life Satisfaction Revisited-1984-2012. In W. Glatzer, L. Camfield, V. Møller, \& M. Rojas, (Eds.) Global Handbook of Quality of Life (pp. 583-596) Springer: Netherlands

Van Praag, B. M., Frijters, P., \& Ferrer-i-Carbonell, A. (2003) The anatomy of subjective well-being. Journal of Economic Behavior \& Organization, 51, 1, 29-49

Veenhoven R., \& Hagerty M. (2006) Rising Happiness in Nations 1946-2004; a reply to Easterlin. Social Indicators Research, 79, 421-436

Weinzierl, M. (2005) Estimating a relative utility function. Harvard University 